\title{
Prognostic Value of ABO Blood Groups in Patients with Glioblastoma Multiforme
}

\author{
Fevzi Coskun Sokmen ${ }^{1}$ and Cengiz Karacin ${ }^{2}$ \\ ${ }^{1}$ Department of Internal Medicine, Abdurrahman Yurtaslan Oncology Training and Research Hospital, Ankara, Turkey \\ ${ }^{2}$ Department of Medical Oncology, Abdurrahman Yurtaslan Oncology Training and Research Hospital, Ankara, Turkey
}

\begin{abstract}
Objective: To investigate relationship among ABO blood groups and prognosis in patients with glioblastoma multiforme (GBM). Study Design: Retrospective observational study.

Place and Duration of Study: Department of Medical Oncology, HSU Dr Abdurrahman Yurtaslan Oncology Training and Research Hospital, Ankara, Turkey, from April 2012 to May 2020.

Methodology: Two hundred and thirty-eight patients with the diagnosis of GBM were retrospectively reviewed. Data regarding age, gender, surgery (total or subtotal), type (chemotherapy (CT) or radiotherapy (RT)) and duration of adjuvant therapies, comorbid conditions, ABO blood groups were analysed for survival. Median overall survival (OS) was estimated using KaplanMeier method. Cox regression model was used to identify independent prognostic factors.

Results: Median age was 57 years (range: 20-83); and 57.6\% were male in the study population. The blood group was blood group $A$ in $45.0 \%$, blood group $B$ in $14.7 \%$, blood group $A B$ in $5.4 \%$, and blood group $O$ in $34.9 \%$ of patients. Median $0 S$ was 22 months in blood group $O$ whereas 14 months in blood group $A, 11$ months in blood group $B$ and 6 months in blood group $A B$ $(p=0.027)$. The median OS was shorter in non-O blood groups when compared to blood group $O$ (13.0 vs. 22.0; $p=0.008$ ). In addition advanced age, subtotal resection and lack of adjuvant therapy (chemotherapy and/or radiotherapy), non-0 blood group were identified as independent poor prognostic factor in multivariate analysis (HR: $1.39 ; p=0.033$ ).

Conclusion: An association was detected among ABO blood groups and prognosis in patients with GBM. It was observed that blood groups significantly affected survival and that median survival was significantly shorter in Non-O blood groups when compared blood group 0 .
\end{abstract}

Key Words: Glioblastoma multiforme, ABO blood group, Prognosis, Survival.

How to cite this article: Sokmen FC, Karacin C. Prognostic Value of ABO Blood Groups in Patients with Glioblastoma Multiforme. J Coll Physicians Surg Pak 2020; 30(07):713-716.

\section{INTRODUCTION}

ABO blood group antigens are expressed not only on the surface of erythrocytes but also on the surfaces of other normal (epithelial cells, neurons, vascular endothelium, platelets) and pathological cells. ${ }^{1}$ The blood group antigens $A$ and $B$ are formed as a result of a series of enzymatic events catalysed via glycosyltransferases encoded by $\mathrm{ABO}$ blood groupgene. ${ }^{2}$ The $\mathrm{ABO}$ enzyme has an important role in intercellular adhesion, cellular membrane signalling and immune system response. ${ }^{3}$ It is thought that glycosyltransferase alterations can cause cancer development. ${ }^{4,5}$

Correspondence to: Fevzi Coskun Sokmen, Department of Intermal Medicine, Abdurrahman Yurtaslan Oncology Training and Research Hospital, Ankara, Turkey

E-mail: fcoskunsokmen@gmail.com

Received: June 11, 2020; Revised: July 20, 2020;

Accepted: July 21, 2020

DOI: https://doi.org/10.29271/jcpsp.2020.07.713
In addition, it was shown that alterations in 9q34, where ABO blood group gene is localised, cause tumor formation in previous studies. ${ }^{4}$ The relationship among ABO blood groups and cancer has been investigated in many studies ${ }^{6,7}$ In several studies, blood group A was defined as a risk factor for gastric and pancreatic cancers. ${ }^{6,7}$ Contradictory results have been reached in studies investigating relationship among $\mathrm{ABO}$ blood groups and brain tumors. ${ }^{8,9}$ In some studies, it was shown that blood group A enhanced while blood group 0 decreased risk for malignant glial tumor. ${ }^{8}$ On the other hand, no relationship was detected among $\mathrm{ABO}$ blood groups and risk for malignant glial tumor in remaining studies. $^{9}$

It was shown that soluble intercellular adhesion molecule-1 (ICAM-1) prevented attachment of lymphocytes to endothelial cells. ${ }^{10}$ It is thought that low ICAM-1 levels facilitate adhesion of some cancer cells to endothelial cells in patients with non-0 blood group, resulting in accelerated tumor metastasis. ${ }^{10,11}$ Based on this hypothesis, prognostic value of $A B O$ blood group was evaluated in many cancer types. Some studies showed that survival was longer in pancreatic cancer patients with blood group $\mathrm{O}$ when compared to those with non-O blood groups. ${ }^{12,13}$ 
Similar results were shown in studies on urinary system cancers (renal cell cancer, bladder cancer), demonstrating that blood group $\mathrm{O}$ is an independent predictive factor for mortality. ${ }^{1}$ However, in the literature, there are some studies indicating that there is no relationship between $A B O$ blood groups and cancer prognosis. $^{1}$

Only two studies have been published on prognostic value of $A B O$ blood groups in glioma so far, showing that $A B O$ blood group has no prognostic value. ${ }^{14,15}$ However, number of patients $(n=76)$ was extremely low in one of these studies while the relationship among ABO blood groups and prognosis wasassessed in a heterogeneous patient group in the other. In this study, the authors aimed to investigate prognostic value of $A B O$ blood groups in a homogeneous group of patients with glioblastomamultiforme (GBM).

\section{METHODOLOGY}

In this retrospective observational study, 238 patients with GBM were assessed who were admitted to Medical Oncology Clinic from April 2012 to May 2020 following the approval by the institutional Ethical Review Board. Inclusion criteria were age $\geq 18$ years, histologically confirmed diagnosis of GBM, underwent surgery for GBM. The patients aged $<18$ years, those with GBM diagnosed by radiological imaging alone, and those without available blood group data were excluded.

Data regarding age, gender, date of diagnosis, histopathological findings, surgery (total or subtotal), type [chemotherapy (CT) or radiotherapy (RT)] and duration of adjuvant therapies, comorbid conditions, $\mathrm{ABO}$ blood groups, date of final communication and date of death were extracted from hospital database. In addition, ABO blood group distribution of patients included was compared with distribution of voluntarily donated blood to the Turkish Red Crescent Society.

The overall survival (OS) was calculated according to ABO blood group of patients. The patients were stratified into two groups: those with blood group $\mathrm{O}$ and those with non-O blood groups. The groups were compared regarding clinic pathologicalcharacteristics and OS.

For descriptive statistics, qualitative variables were expressed as frequencies and percentages, while quantitative as median (IQR). The conformity of numerical data to normal distribution was assessed using the Kolmogorov-Smirnov test. Pearson Chi-square or Fisher Exact test was used to compare categorical variables. Overall survival was defined as time from diagnosis to death, due to any causes. Median OS was calculated using Kaplan-Meier survival curve; and Log-rank test was used to compare median OS between groups. All parameters found to influence OS in univariate analysis were entred to Cox regression model. Multivariate analysis was used to identify independent prognostic factors for OS. All statistical analyses were performed using IBM SSPS Statistics for Windows version 20.0 software (IBM Corp., Armonk, NY). All analyses were twosided and a p-value $<0.05$ was considered as statistically significant.

\section{RESULTS}

Median age was 57 years (range: $20-83$ ) in 238 patients. Of the patients, $57.6 \%$ were male and $42.4 \%$ were female. Of the patients, 152 (63.9\%) had comorbidities, 141 (59.2\%) had limited disease and total resection of the tumour. When adjuvant treatments were examined, 188 (79.0\%) patients received temozolomide, and 221 (92.9\%) patients received radiotherapy.

Table I: Acomparison of the blood group O and non-O.

\begin{tabular}{|c|c|c|c|}
\hline & $\begin{array}{c}0 \text { blood group } \\
n: 83\end{array}$ & $\begin{array}{c}\text { Non-0 } \\
\text { blood group } \\
n: 155\end{array}$ & $\mathbf{p}$ \\
\hline $\begin{array}{l}\text { Age } \\
<57 \\
\geq 57\end{array}$ & $\begin{array}{l}44(53.0) \\
39(47.0)\end{array}$ & $\begin{array}{l}76(49.0) \\
79(51.0)\end{array}$ & 0.558 \\
\hline $\begin{array}{l}\text { Gender } \\
\text { Male } \\
\text { Female }\end{array}$ & $\begin{array}{l}49(59.0) \\
34(41.0)\end{array}$ & $\begin{array}{l}88(56.8) \\
67(43.2)\end{array}$ & 0.737 \\
\hline $\begin{array}{l}\text { Surgery } \\
\text { Total } \\
\text { Subtotal }\end{array}$ & $\begin{array}{l}44(53.0) \\
39(47.0)\end{array}$ & $\begin{array}{l}97(62.6) \\
58(37.4)\end{array}$ & 0.152 \\
\hline $\begin{array}{l}\text { Adjuvant temozolamide } \\
\text { Yes } \\
\text { No }\end{array}$ & $\begin{array}{l}69(83.1) \\
14(16.9)\end{array}$ & $\begin{array}{c}119(76.8) \\
36(23.2)\end{array}$ & 0.251 \\
\hline $\begin{array}{l}\text { Adjuvant RT } \\
\text { Yes } \\
\text { No }\end{array}$ & $\begin{array}{c}80(96.4) \\
3(3.6)\end{array}$ & $\begin{array}{c}141(91.0) \\
14(9.0)\end{array}$ & 0.186 \\
\hline $\begin{array}{l}\text { Comorbidity } \\
\text { Yes } \\
\text { No }\end{array}$ & $\begin{array}{l}51(61.4) \\
32(38.6)\end{array}$ & $\begin{array}{c}101(65.2) \\
54(34.8)\end{array}$ & 0.570 \\
\hline
\end{tabular}

Table II. Univariate analysis of factors affecting median 0 S.

\begin{tabular}{|c|c|c|}
\hline & $\begin{array}{l}\text { Median OS, } \\
\text { months }(95 \% \mathrm{Cl})\end{array}$ & $p$ \\
\hline $\begin{array}{l}\text { Age } \\
<57 \\
\geq 57\end{array}$ & $\begin{array}{l}25.0(20.1-29.9) \\
8.0(5.5-10.5)\end{array}$ & $<0.001$ \\
\hline $\begin{array}{l}\text { Surgery } \\
\text { Total } \\
\text { Subtotal }\end{array}$ & $\begin{array}{l}19.0(15.5-22.5) \\
11.0(7.0-15.0)\end{array}$ & 0.001 \\
\hline $\begin{array}{l}\text { Adjuvant temozolamide } \\
\text { Yes } \\
\text { No }\end{array}$ & $\begin{array}{l}21.0(18.1-23.9) \\
3.0(1.5-4.5)\end{array}$ & $<0.001$ \\
\hline $\begin{array}{l}\text { Adjuvant RT } \\
\text { Yes } \\
\text { No }\end{array}$ & $\begin{array}{l}18.0(14.3-21.7) \\
3.0(1.5-4.5)\end{array}$ & $<0.001$ \\
\hline $\begin{array}{l}\text { Comorbidity } \\
\text { Yes } \\
\text { No }\end{array}$ & $\begin{array}{l}12.0(8.3-15.7) \\
23.0(19.9-26.1)\end{array}$ & 0.005 \\
\hline $\begin{array}{l}\text { Blood group } \\
\text { O } \\
\text { Non-O }\end{array}$ & $\begin{array}{l}22.0(15.5-28.5) \\
13.0(9.5-16.5)\end{array}$ & 0.008 \\
\hline
\end{tabular}

The number of patients with $A, B, A B$ and $O$ blood groups in the GBM group were 107 (45.0\%), 35 (14.7\%), 13 (5.4\%) and 83 $(34.9 \%)$, respectively; in the control group, it was 48860 (43.8\%), 17000 (15.2\%), 7991 (7.2\%), and 37690 (33.8\%). There was no significant difference in $\mathrm{ABO}$ blood group distribution when compared with distribution of volunteers donated blood to Turkish Red Crescent Society $(p=0.764)$. 
The age and gender distribution was comparable between patients with blood group $\mathrm{O}$ and non-O blood groups; in addition, there was also no significant difference in type of surgery, adjuvant therapy and comorbidity between groups (Table I).

Median follow-up was 13.0 months (IQR: 5.0-28.0 months) and median OS was 16.0 months ( $95 \% \mathrm{Cl}: 12.4-19.6$ months). In the univariate analysis, median OS was found to be longer in patients aged $<57$ years, those underwent total resection and those received adjuvant temozolamide and/or radiotherapy while shorter in patients with comorbid conditions and those with non-O blood group (Table II). Median OS was 22.0 months (95\% Cl: 15.5-28.5 months) in the blood group 0; whereas, 14 months (95\% Cl: 9.9-18.1 months) in the blood group A, 11 months ( $95 \% \mathrm{Cl}: 8.2-13.8$ months) in the blood group $B$ and 6 months (95\% Cl: $1.6-10.4$ months) in the blood group $A B$ $(p=0.027)$. The median OS was shorter in non-O blood groups (13.0 months; $95 \% \mathrm{Cl}$ : 9.5-16.5 months) when compared to blood group $\mathrm{O}(22.0$ months; $95 \% \mathrm{Cl}$ : 15.5-28.5 months; $\mathrm{p}=0.008$, Figure 1).

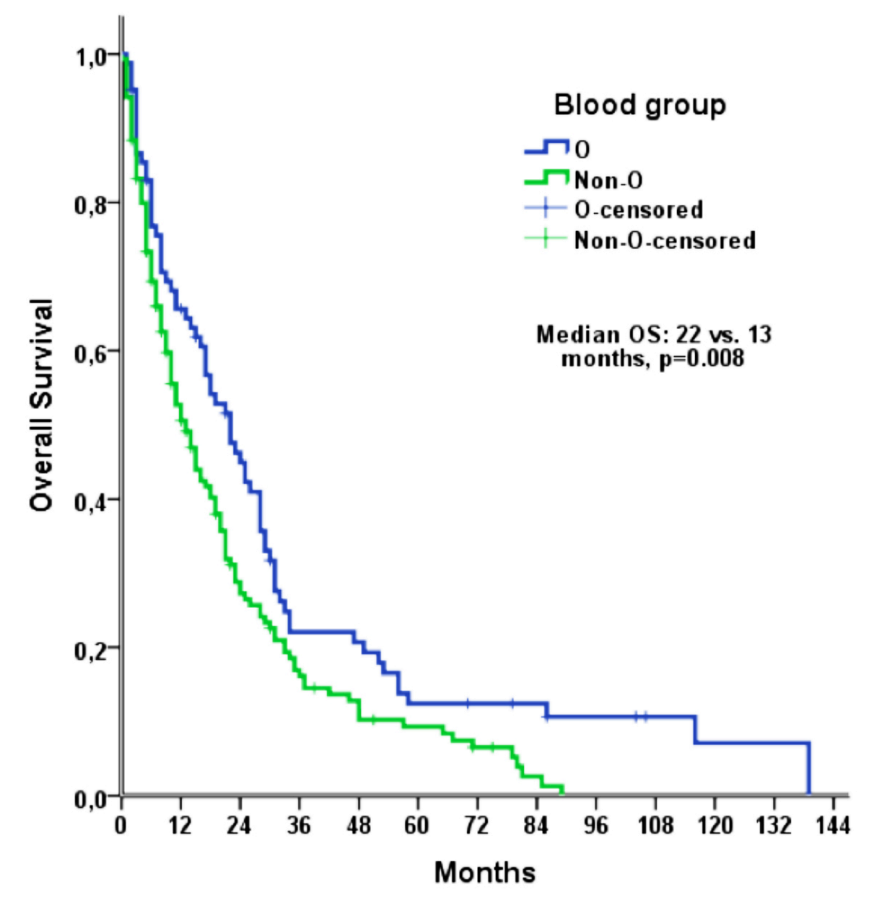

Figure 1: Kaplan-Meier curve of the OS, according to the blood groups.

Cox regression model included age, type of surgery, adjuvant therapy (temozolomide or radiotherapy), comorbidity and $A B O$ blood group, all of which was found to influence on OS in univariate analysis. The advanced age (HR: 1.64, (95\% $\mathrm{Cl}: 1.20-2.23), p=0.002)$, subtotal resection (HR: $1.50,(95 \%$ $\mathrm{Cl}: 1.12-2.02), \mathrm{p}=0.007)$, lack of adjuvant chemotherapy (HR: $3.40,(95 \% \mathrm{Cl}: 2.24-5.18), \mathrm{p}<0.001)$, lack of adjuvant radiotherapy (HR: 2.22, (95\% Cl:1.21-4.07), $p=0.010)$, and non-0 blood group (HR: 1.39, (95\% Cl:1.03-1.88), $p=0.033$ ) were identified as independent poor prognostic factor in multivariateanalysis.

\section{DISCUSSION}

In this study, prognostic value of $\mathrm{ABO}$ blood groups was investigated in patients with GBM. This is the first study showing prognostic value of $A B O$ blood groups in patients with GBM. In this study, overall survival was found to be shorter in GBM patients with non-O ABO blood groups than those with blood group 0 .

In a study on patients with glioma (low-grade astrocytoma, anaplastic astrocytoma and GBM), Alkan et al. showed that ABO blood groups had no prognostic value. ${ }^{14}$ However, only $45.5 \%$ of patients received adjuvant chemotherapy; whereas, $46.6 \%$ received adjuvant radiotherapy in that study. ${ }^{14}$ In this study, $79.0 \%$ and $92.9 \%$ of the patients received adjuvant chemotherapy and radiotherapy, respectively. The differences in adjuvant therapy were reflected in overall survival. Median OS was 12.9 months in the study by Alkan et al. whereas, it was 16.0 months in this study. ${ }^{14}$ In addition, the median follow-up was 18.0 months in the present study; however, it was not specified in the study by Alkan et al. The difference detected in prognostic value of $A B O$ blood groups in our may be due to shorter OS, lower rates of adjuvant therapies and, presumably, shorterduration of follow-up in the study by Alkan etal. In a retrospective study on 72 patients with GBM, Akca et al. found no correlation among $A B O$ blood groups and prognosis. ${ }^{15}$ In the study, number of patients with blood groups $O, A, B$ and $A B$ were 23, 33, 9 and 7, respectively. ${ }^{15}$ The reason may be that the number of patients was insufficient for prognostic analyses in the study by Akca etal.

In previous studies, it was shown that $A B O$ blood groups has prognostic value on pancreas and bladder cancers. ${ }^{1,13}$ In agreement with the present study, it was shown that non-0 blood groups negatively affected prognosis in studies on pancreas and bladder cancer. ${ }^{1,13}$ In this study, overall survival was found to be short in patients with non-O blood groups. Moreover, comparable clinical characteristics and treatment regimens in patients with blood group $\mathrm{O}$ and those with non-O blood groups strengthened our finding that non-O blood groups had independent impact on survival. In multivariate analysis including ABO blood groups, age, adjuvant therapy, type of surgery and comorbidity, it was found that non-O blood group is an independent prognostic factor in GBM patients underwent surgical treatmentin ourstudy.

The mechanism, which ABO blood groups affect cancer prognosis, is unclear. It has been proposed that variation in $A B O$ blood groups can lead differences in host's inflammatory response against tumor cells. ${ }^{16}$ In addition, a link was detected between $A B O$ gene polymorphism and TNF-alpha and adhesion molecules (ICAM-1, E-selectin and P-selectin) ${ }^{16}$ It is well-known that adhesion molecules play an important role in the spread of cancer cells. ${ }^{16}$ It was also shown that ICAM-1 levels are lower in individuals with blood group 0 when compared to those with non-O blood groups. ${ }^{16}$ Tumoral cell adhesion to endothelial tissue is facilitated by reduced ICAM-1 levels, enhancing tumor cellspread. ${ }^{16}$

This study has some limitations. In our study, we failed to obtain 
data regarding $O$ (6)-methylguanine-DNA methyltransferase (MGMT) promoter, which is known to have prognostic value in GBM. Thus, we could not be able to show MGMT status, relationship with $A B O$ blood groups and how did such a relationship influence on survival. In addition, Eastern Cooperative Oncology Group (ECOG) scores were unavailable in these patients; thus we could not be able to include ECOG scores in survival analysis. The authors did not specify data regarding recurrence and treatmentregimens after recurrence. However, the authors think that such missing information had no influence on these results since prognostic value of $A B O$ blood groups was investigated but not predictive value.

\section{CONCLUSION}

This study showed prognostic value of $A B O$ blood groups in GBM patients who underwent surgery. It was shown that overall survival was shorter in GBM patients with non-O blood groups compared to those with blood group 0 . Further studies investigating prognostic value of $A B O$ blood groups and underlying mechanism in patients with GBM are needed.

\section{ETHICAL APPROVAL:}

Ethics Committee approval was received from the Ethics Committee of University of Health Sciences, Dr Abdurrahman Yurtaslan Oncology Training and Research Hospital (Number:E-91/1, April 7, 2020).

\section{PATIENTS' CONSENT:}

Informed consents were obtained from all participants or their family, included in the study.

\section{CONFLICT OF INTEREST:}

Authors declared no conflict of interest.

\section{AUTHORS' CONTRIBUTION:}

FCS: Conception and design, analysis and interpretation of data, drafting of manuscript.

CK: Conception and design, analysis and interpretation of data, drafting of manuscript, reviewed the paper, advised and final approval.

\section{REFERENCES}

1. Franchini M, Liumbruno GM and Lippi G. The prognostic value of $A B O$ blood group in cancer patients. Blood Transfus 2016; 14(5):434-40. doi: 10.2450/2015.0164-15.

2. Yamamoto F, Cid E, Yamamoto M, Blancher A. ABO research in the modern era of genomics. Transfus Med Rev 2012; 26(2):103-18. doi: 10.1016/j.tmrv.2011.08.002.

3. Hakomori S. Tumor-associated carbohydrate antigens defining tumor malignancy: Basis for development of anticancer vaccines. The molecular immunology of complex carbohydrates-2. Springer 200; 369-402.

4. Bayani J, Pandita A, Squire JA. Molecular cytogenetic analysis in the study of brain tumors: Findings and applications. Neurosurg Focus 2005; 19(5):E1. doi: 10.3171/foc.2005.19.5.2.

5. Roseman S. Reflections on glycobiology. J Biol Chem 2001; 276(45):41527-42. doi: 10.1074/jbc.R100053200.

6. Edgren G, Hjalgrim H, Rostgaard K, Norda R, Wikman A, Melbye $M$, et al. Risk of gastric cancer and peptic ulcers in relation to $A B O$ blood type: A cohort study. Am J Epidemiol 2010; 172(11):1280-5. doi: 10.1093/aje/kwq299.

7. Wolpin BM, Chan AT, Hartge P, Chanock SJ, Kraft P, Hunter $D J$, et al. ABO blood group and the risk of pancreatic cancer. J Natl Cancer Inst 2009; 101:424-31.

8. Allouh MZ, Al Barbarawi MM, Hiasat MY, Al-Qaralleh MA, Ababneh El. Glioblastoma and ABO blood groups: Further evidence of an association between the distribution of blood group antigens and brain tumours. Blood Transfus 2017; 15(6):543-7. doi: 10.2450/2016.0041-16.

9. Cote DJ, Downer MK, Zoltick ES, Smith TR, Stampfer MJ. ABO blood group and risk of glioma. Neuro Oncol 2017; 19(6):871-3. doi: 10.1093/neuonc/nox013.

10. Witkowska AM, Borawska MH. Soluble intercellular adhesion molecule-1 (sICAM-1): An overview. Eur Cytokine Netw 2004; 15(2):91-8.

11. Kobayashi H, Boelte KC, Lin PC. Endothelial cell adhesion molecules and cancer progression. Curr Med Chem 2007; 14(4):377-86. doi: 10.2174/092986707779941032.

12. Ben Q, Wang K, Yuan Y, Li Z. Pancreatic cancer incidence and outcome in relation to $A B O$ blood groups among Han Chinese patients: A case-control study. Int J Cancer 2011; 128(5):1179-86. doi: 10.1002/ijc.25426.

13. Rahbari NN, Bork U, Hinz U, Leo A, Kirchberg J, Koch M, et al. ABO blood group and prognosis in patients with pancreatic cancer. BMC Cancer 2012; 12:319. doi: 10.1186/1471-2407-12-319.

14. Alkan A, Yazıcı G, Cengiz M, Karakaş Y, Çelik I, Kars A, et al. The role of $A B O$ blood groups in glial neoplasms. $\mathrm{Br} J$ Neurosurg 2019; 33(1):43-6. doi: 10.1080/02688697. 2018.1522415.

15. Akca Z, Mutlu H, Erden A, Buyukcelik A, Sezer Y, Inal A. The relationship between $A B O$ blood group and glioblastoma multiforme. Med Science 2014; 3(4):1639-47. doi: 10.5455/ medscience.2014.03.8160.

16. Melzer D, Perry JR, Hernandez D, Corsi AM, Stevens K, Rafferty I, et al. A genome-wide association study identifies protein quantitative trait loci (pQTLS). PLoS Genetics 2008; 4(5): e1000072. doi: 10.1371/journal.pgen.1000072. 